Original Research Article

\title{
A randomized controlled open label comparative clinical study of cephalexin versus doxycycline in patients with acne vulgaris in a hospital based population of South India
}

\author{
Prithwijit Banerjee $^{1 *}$, Somnath Maity ${ }^{1}$, Aditya Bubna ${ }^{2}$, Manisha Das ${ }^{1}$
}

\begin{abstract}
${ }^{1}$ Department of Pharmacology, College of Medicine and Sagore Dutta Hospital, Kamarhati, Kolkata, West Bengal, India ${ }^{2}$ Department of Dermatology, Sri Ramachandra Medical College and Research Institute, Porur, Chennai, Tamil Nadu, India
\end{abstract}

Received: 24 May 2017

Accepted: 24 June 2017

\section{*Correspondence to:}

Dr. Prithwijit Banerjee, Email: drprithwijit@gmail.com

Copyright: (C) the author(s), publisher and licensee Medip Academy. This is an openaccess article distributed under the terms of the Creative Commons Attribution NonCommercial License, which permits unrestricted noncommercial use, distribution, and reproduction in any medium, provided the original work is properly cited.

\begin{abstract}
Background: Oral antibiotics are frequently used for acne vulgaris. Cephalexin has documented some success against acne vulgaris in earlier studies. Here the efficacy and safety of Cephalexin have been compared against the standard therapy of Doxycyline.

Methods: From September 2010 to June 2011, 100 patients of moderate Acne vulgaris were randomized into two groups to receive oral Doxycyline $(100 \mathrm{mg}$ once daily) or Cephalexin (500mg thrice daily) in an open label manner for eight weeks. All participants were allowed to use topical 5\%Benzoyl peroxide gel twice daily. Efficacy was measured in terms of reduction in the number of facial comedones and inflammatory lesions from baseline after eight weeks.

Results: 44 patients from Cephalexin group and48 patients from Doxycyline group completed the study. Both drugs have significantly decreased comedone count as well as the inflammatory lesion count after eight weeks. However, Doxycycline appeared better in terms of Comedone count $(14.5 \pm 3.07$ versus $12.9 \pm 4.31, \mathrm{p}=0.045)$ as well as inflammatory lesion count $(8.64 .1 \pm 2.14$ versus $7.67 \pm 2.46, \mathrm{p}=0.047)$ at the end. The total adverse event was slightly more with Cephalexin $(6.81 \%$ versus $6.25 \%, \mathrm{p}=0.912)$, where Diarrhoea remained the commonest adverse effect $(4.54 \%)$.

Conclusions: Although for the first time oral Cephalexin has displayed efficacy against moderate acne vulgaris in a prospective clinical study, it appeared inferior to Doxycycline over eight weeks. Therefore, it becomes an option only when other oral antibiotics are contraindicated or not tolerated.
\end{abstract}

Keywords: Acne vulgaris, Benzoyl peroxide, Cephalexin, Doxycycline

\section{INTRODUCTION}

Acne vulgaris is one of the most common skin disorders, affecting $90 \%$ of the people worldwide sometime or the other in their life. ${ }^{1}$ Teenagers and young adults are usually affected, though $10-20 \%$ of the adult population may experience some form of the skin disorder. ${ }^{2}$

Multiple factors including excess sebum production, follicular hyper keratinization, colonization of bacteria like Propionibacterium acnes (P. acnes), and resultant inflammation are responsible for the pathogenesis of acne. $^{3}$

The clinical presentation of acne can vary from noninflammatory comedones to inflammatory nodules. ${ }^{4}$

Since the involvement of the face is frequent, various psychological abnormalities like lack of confidence, depression, anxiety and even suicidal tendencies have been associated with patients suffering from moderate to severe form of Acne vulgaris. ${ }^{5-7}$ 
Long term oral antibiotics are routinely administered worldwide as a part of standard therapy in the management of moderate to severe acne vulgaris with inflammatory components. ${ }^{8,9}$ Based on the response, such therapy can be extended for 3 months. ${ }^{8}$ Tetracyclines and its derivatives like Doxycycline and Minocycline are the first choices, while Macrolides, Cotrimoxazole and Trimethoprim come as alternatives. Oral Doxycycline has been successfully used at a dose range of 50-200mg per day among the patients of acne. ${ }^{10}$ Addition of a topical agent like Benzoyl peroxide (BPO) to long term oral antibiotic regimen is recommended as it reduces the development of antibiotic-resistance. ${ }^{11}$

Although conventional systemic antibiotics for acne are often successful, many patients do not improve or are unable to tolerate medications because of the associated side effects. ${ }^{12}$ Moreover; the inevitable emergence of antibiotic-resistant strains of $P$. acnes has further complicated the management of acne. ${ }^{13}$

In spite of being used in skin and soft tissue infections, Cephalosporins have been rarely tried in acne since their hydrophilic property prevents the penetration into the microcomedones. ${ }^{14}$ An anecdotal report showed two patients experienced significant improvement of their acne after using Cephalosporins actually for some other conditions. ${ }^{15}$ Later, antibiotic susceptibility studies have also displayed the efficacy of Cephalexin against $P$. acnes, isolated from the acne vulgaris lesions. ${ }^{16,17}$ Lately, there was clinical evidence as well suggesting the role of Cephalexin in the treatment of acne vulgaris. The study however was a retrospective analysis and had a few limitations like lack of standard acne severity grading system and non standardized treatment length. ${ }^{12}$

Therefore it gave us the opportunity for the first time to evaluate and compare the efficacy of oral Cephalexin in the management of acne vulgaris against one of the standard drug for a fixed treatment-duration and by using a standardized evaluation technique.

\section{METHODS}

This prospective randomized controlled evaluator-blinded study was conducted from January 2011 to August 2011 at the outpatient department of the Dermatology, Sri Ramachandra Medical College and Research centre, Chennai. Patients of either gender aged above 12 years, suffering from moderate degree of inflammatory acne vulgaris were included for the study. Patients suffering from severe form of acne vulgaris, drug induced acne and those who took any of the study antibiotic in last two months or known to have hypersensitivity to any of them were spared from our study. Pregnant and lactating mothers were also excluded. A total of 136 patients were initially screened and finally 100 were enrolled for the study after they fulfilled the eligibility criteria. Voluntary written informed consent was taken from all the participants after explaining the study protocol in detail and giving adequate time to decide on their participation in the clinical study. The informed consent form was available in English, Hindi and regional language (Tamil).

Hundred patients were randomized by computerized ten block simple randomization process into two groups to receive either Doxycycline or Cephalexin in an open label manner for a period of eight weeks. Doxycycline was administered at a fixed dose of $100 \mathrm{mg}$ tablet per day after meal. Cephalexin on the other hand was given as $500 \mathrm{mg}$ capsule thrice daily before meals. All patients were allowed to apply 5\% Benzoyl peroxide gel over the lesions at night during the entire study period.

The baseline features like demographic details, duration of the illness, history of previous antibiotic usage, facial comedone and inflammatory lesion counts and systemic examination findings were noted in a specially designed case report form. Each participant underwent detailed local and systemic examination during the subsequent visits at fourth and eighth week by a dermatologist.

Efficacy was measured in terms of reduction of facial comedone count and inflammatory lesion counts from the baseline after eight weeks of therapy. Adverse events, if any, were also noted down. Finally the data was tabulated and analyzed by using SPSS -17 . A $p$ value $\leq 0.05$ was considered significant in our study.

\section{RESULTS}

Table 1: Baseline characteristics of the study subjects who completed the study according to the study drug assignment.

\begin{tabular}{|llll|}
\hline Characteristics & $\begin{array}{l}\text { Cephalexin } \\
\mathbf{n = 4 4}\end{array}$ & $\begin{array}{l}\text { Doxycycline } \\
\mathbf{n = 4 8}\end{array}$ & $\begin{array}{l}\mathbf{p} \\
\text { value }\end{array}$ \\
\hline Male & $\begin{array}{l}21 \\
(47.72 \%)\end{array}$ & $20(41.66 \%)$ & $0.675 \#$ \\
\hline $\begin{array}{l}\text { Mean age } \pm \text { SD } \\
\text { (years) }\end{array}$ & $17.65 \pm 11.7$ & $19.2 \pm 13.91$ & $0.566^{\wedge}$ \\
\hline $\begin{array}{l}\text { Duration of } \\
\text { complaints } \pm \text { SD } \\
\text { (months) }\end{array}$ & $7.11 \pm 4.55$ & $7.83 \pm 5.18$ & $0.482^{\wedge}$ \\
\hline $\begin{array}{l}\text { History of } \\
\text { previous oral } \\
\text { antibiotic usage } \\
\text { for acne }\end{array}$ & 13 & $15(31.25 \%)$ & $0.859 \#$ \\
\hline $\begin{array}{l}\text { Mean facial } \\
\text { comedone } \\
\text { count } \pm \text { SD }\end{array}$ & $23.84 \pm 4.65$ & $25.02 \pm 4.12$ & $0.2^{\wedge}$ \\
\hline $\begin{array}{l}\text { Mean facial } \\
\text { inflammatory } \\
\text { lesion } \\
\text { count } \pm \text { SD }\end{array}$ & $13.77 \pm 2.55$ & $13.79 \pm 2.6$ & $0.97^{\wedge}$ \\
\hline
\end{tabular}

$\wedge p$ value obtained by using Student's t test.

\# $\mathrm{p}$ value obtained by using Chi square test. 
Out of 100 patients enrolled for the study 92 have finally completed; 44 from the Cephalexin and 48 from Doxycycline group. Six participants from Cephalexin group and two from Doxycycline group were lost to follow up after randomization. The detailed patient flow pattern during the study period of eight weeks has been described in Figure 1. The baseline features of the two study groups are mentioned in Table 1, which shows that both groups were comparable at the beginning of the study.

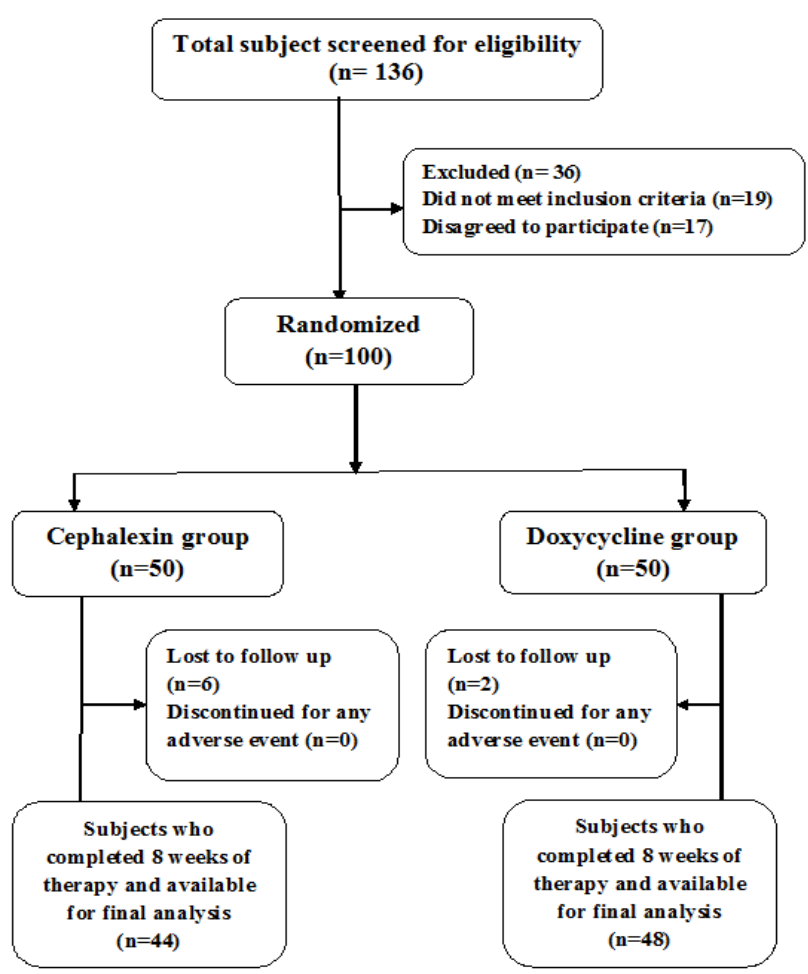

Figure 1: Patients flow during the study.

The changes in the facial comedone count and inflammatory lesion count during the course of the study are given in Table 2 and Table 3 respectively. Based on our findings, both Cephalexin and Doxycycline have significantly decreased comedone count as well as the inflammatory lesion count from the baselinesgroup at the end of eight weeks ( $p$ value $<0.001$ ).

Table 2: Facial comedone counts in each study group after $4^{\text {th }}$ and $8^{\text {th }}$ week of therapy.

\begin{tabular}{|c|c|c|c|}
\hline $\begin{array}{l}\text { Facial } \\
\text { comedone } \\
\text { count }\end{array}$ & $\begin{array}{l}\text { Cephalexin } \\
(n=44)\end{array}$ & $\begin{array}{l}\text { Doxycycline } \\
(n=48)\end{array}$ & p value \\
\hline Baseline & $23.84 \pm 4.65$ & $25.02 \pm 4.12$ & $0.2^{\wedge}$ \\
\hline $4^{\text {th }}$ week & $19.75 \pm 3.28$ & $18.75 \pm 4.84$ & $0.25^{\wedge}$ \\
\hline $8^{\text {th }}$ week & $14.5 \pm 3.07$ & $12.9 \pm 4.31$ & $0.045^{\wedge}$ \\
\hline $\mathrm{p}$ value* & $<0.001$ & $<0.001$ & \\
\hline
\end{tabular}

However, the reductions of both comedone count and the inflammatory lesion count from the baseline were significantly higher with Doxycycline than Cephalexin after eight weeks of therapy. Unlike the comedone count, facial inflammatory lesion count started showing significant improvement from baseline at as early as fourth week of treatment (Table 2 and 3 ).

Table 3: Facial inflammatory lesion count in each study group after $4^{\text {th }}$ and $8^{\text {th }}$ week of therapy.

\begin{tabular}{|c|c|c|c|}
\hline $\begin{array}{l}\text { Facial } \\
\text { inflammatory } \\
\text { lesion count }\end{array}$ & $\begin{array}{l}\text { Cephalexin } \\
(n=44)\end{array}$ & $\begin{array}{l}\text { Doxycycline } \\
(n=48)\end{array}$ & p value \\
\hline Baseline & $13.77 \pm 2.55$ & $13.79 \pm 2.6$ & $0.97^{\wedge}$ \\
\hline $4^{\text {th }}$ week & $11.41 \pm 2.59$ & $9.9 \pm 2.28$ & $0.003^{\wedge}$ \\
\hline $8^{\text {th }}$ week & $8.64 \pm 2.14$ & $7.67 \pm 2.46$ & $0.047^{\wedge}$ \\
\hline $\mathrm{p}$ value* & $<0.001$ & $<0.001$ & \\
\hline
\end{tabular}

Table 4 depicts the safety profile of both the drugs in terms of adverse effects encountered during the study period. These effects were mild, transient and self limiting in nature. Total adverse effects appeared to be slightly higher with Cephalexin, which was statistically insignificant $(p=0.912)$. Diarrhea was found to be the commonest side effect with Cephalexin (4.54\%). On the other hand diarrhea, skin rash and headache were observed with Doxycycline, each having equal incidence of $2.08 \%$ during the study.

Table 4: Comparison of safety profiles of both the study drugs.

\begin{tabular}{|lll|}
\hline Adverse event & $\begin{array}{l}\text { Cephalexin } \\
(\mathbf{n = 4 4 )}\end{array}$ & $\begin{array}{l}\text { Doxycycline } \\
(\mathbf{n}=48)\end{array}$ \\
\hline Diarrhea & $2(4.54 \%)$ & $1(2.08 \%)$ \\
\hline Skin rash & $1(2.27 \%)$ & $1(2.08 \%)$ \\
\hline Headache & 0 & $1(2.08 \%)$ \\
\hline Total adverse events & $3(6.81 \%)$ & $3(6.25 \%)$ \\
\hline $\begin{array}{l}\text { p value of total adverse } \\
\text { event }\end{array}$ & $0.912 \#$ & \\
\hline
\end{tabular}

\# p value obtained by using Chi square test.

\section{DISCUSSION}

Acne vulgaris is an extremely prevalent skin disorder among the teenagers, which regardless of the severity can significantly affect the quality of life. ${ }^{18,19}$ Medical intervention therefore, can make a big difference to such patients either by complete clearing or causing significant improvement of the condition. ${ }^{20}$ The main principles of treatment of acne consist of elimination of comedones by normalization of follicular keratinization, decreasing sebaceous gland activity and reduction in the population of $P$. acne and thereby reducing the inflammatory process. $^{2}$ Oral antibiotics have been used to treat acne 
vulgaris since $1950 .{ }^{21}$ And today, approximately $66 \%$ of antibiotic usage in Dermatology is for acne. ${ }^{22}$ Still many patients do not improve with the traditional course of antibiotics either due to the development of antimicrobial resistance by $P$. acne or the intolerance issues associated with those antibiotics. ${ }^{12,22}$ These patients either live with the condition or consider other options like oral contraceptives, spironolactone, or isotretinoin, each with its own risk of side effects. ${ }^{12}$

Multiple factors like efficacy, compliance, tolerability, cost-effectiveness and the potential for development of bacterial resistance should be taken into account while selecting an appropriate oral antibiotic for acne. ${ }^{3}$ Although the efficacy of Cephalexin in acne vulgaris has been recently documented, no head to head comparative trial was ever done. Therefore, this study was designed to analyze its efficacy against the standard therapy of Doxycycline for the management of moderate acne vulgaris over a period of eight weeks in a hospital based population of South India. Except Isotretinoin, which is a reserved drug, nothing really has come up in the space of oral agent for acne vulgaris in the past few decades. Although newer treatment options like physical modalities and devices are emerging, their efficacies nevertheless have been limited.

Based on our observation, both Cephalexin and Doxycycline have significantly reduced the comedone count and inflammatory lesion count from baselines after eight weeks of therapy ( $p$ value <0.001). However, considering these two parameters, Doxycycline appeared to be a better agent at the end of our study.

Doxycycline has better pharmacokinetic profile than its parent molecule tetracycline in terms of rapid oral absorption, longer half life and excellent penetration into the follicles and sebaceous glands. ${ }^{23-26}$ Independent of their well-known antibacterial effect, tetracyclines demonstrate certain important pharmacological actions like regulating the inflammatory pathway and the immune responses. ${ }^{24}$ The anti inflammatory effect is primarily ascribed to the inhibition of metalloproteinase (MMP) and suppression of Hydrolases like $\alpha$ - amylase and phospholipase A2 which are key enzymes for prostaglandin biosynthesis. ${ }^{27-29}$ Besides this, the cyclines limit Neutrophil leucotaxis and suppress the production of cytokines such as tumor necrosis factor- alpha (TNF$\alpha$ ) and interleukins (IL-1 $\beta$, IL-6) by the Neutrophils and Macrophages and thereby interfere with the immunological cascades. ${ }^{27-30}$ They are also known to prevent pathological tissue destruction by scavenging the reactive oxygen species. ${ }^{27}$ Hence, cyclines exert both antibacterial and non-antibacterial properties in combating acne. ${ }^{31}$

Dosing of Doxycycline in acne vulgaris has become another interesting area of research since the drug was found to be significantly effective in few occasions even at a sub antimicrobial dose level (20mg twice daily) while treating moderate facial acne cases. ${ }^{32,33}$ A very recent study with larger sample size has shown that a modified release sub antimicrobial dose of Doxycycline (40mg once daily) was not only effective as $100 \mathrm{mg}$ daily dose but also appeared better in terms of safety in the treatment of moderate to severe inflammatory acne. ${ }^{34}$

Lately, an in vitro study focusing the anti-inflammatory property of Doxycycline also indicated that the drug could be safely used at a low dose (20-40mg daily) in chronic or acute skin diseases where inflammation has to be controlled or prevented. ${ }^{24}$ Perhaps it will take some time for this concept of sub optimal dosing to be included into the acne guidelines. Till then Indian dermatologists continue to prescribe $100 \mathrm{mg}$ daily dose; the same dose we used for our study. ${ }^{35}$

The capacity of some of the antibiotics like Tetracycline, erythromycin and nadifloxacin to inhibit the reactive oxygen species production by the neutrophils is attributable for their effect in inflammatory skin diseases like acne vulgaris. Nevertheless, this effect seemed to be absent with Cephalexin based on in vitro study results at a concentration comparable to the therapeutic blood level. $^{36}$ However, like other beta-lactam antibiotics Cephalexin can form stable covalent complexes at the active site of some of the important mammalian enzymes, which regulate the fundamental physiological processes in mammals. This non -antibacterial property can partly explain their therapeutic role in inflammatory disorders. ${ }^{37}$ The role of CD4+ T-cell mediated immune responses has been also suggested in inflammatory acne as their down regulation is associated with the resolution of acne. ${ }^{38}$ Still we feel the exact mechanism of Cephalexin in acne vulgaris is yet to be ascertained, considering the fact that the penetration of Cephalosporins into the microcomedones is very limited due to the hydrophilic nature of the drug. ${ }^{3}$

One remarkable advantage of Cephalexin is its safety during pregnancy, while drugs like tetracyclines and its derivates, cotrimoxazole, isotretinoin and hormonal therapy are contraindicated. ${ }^{39}$ Although, pregnant ladies were not involved in our study, previous literatures suggest that Cephalexin can be a safer option in such patients, whenever an oral antibiotic is to be administered. ${ }^{40-43}$

Safety wise both the drugs were comparable during the study period of eight months. The total incidence of treatment-related adverse events turned out to be slightly higher among the Cephalexin users than Doxycycline (6.81\% versus $6.25 \%, \mathrm{p}=0.912)$, which was nevertheless statistically insignificant. All the adverse events were mild in nature and were relieved with basic symptomatic management without discontinuing the study drug. Diarrhea was reported from both groups but the incidence was more in Cephalexin arm (4.54\% versus $2.08 \%)$. The diarrheal incidence of Cephalexin in our study closely resembles with that of an earlier observation where the 
drug was evaluated for uncomplicated skin and skin structure infections. ${ }^{44}$ Mild and transient macular skin rash was observed in one patient from each group. In both occasions, it disappeared within two to three days after the discontinuation.

It is also important to realize the emerging problem of antibiotics resistance associated with indiscriminate and long term use of antibiotics in acne vulgaris. The incidence of $P$. acnes antibiotic resistance has jumped from $20 \%$ in 1978 to $62 \%$ in $1996 .{ }^{12}$ This is often attributed to the regional prescription pattern, patient compliance and the genomic variability in $P$. acnes. ${ }^{10,45}$ Quite recently, an Indian study has documented Doxycycline resistance as high as $44.2 \%$ among $52 P$. acnes strains isolated from 80 different patients. Very high degree of resistance against macrolides like Azithromycin (100\%) and Erythromycin (98\%) has been observed in the same study. ${ }^{45}$

Thus, to optimize the use of oral antibiotics in acne vulgaris many guidelines have been developed which dissuade antibiotics monotherapy and subtherapeutic dosing of antimicrobial agents and also recommend the addition of topical agent like Benzoyl peroxide or retinoids. ${ }^{10,46,47}$ In order to minimize the risk of antibiotic resistance, long term antibiotics therapy should be limited to maximum three months and effective alternative treatment modalities must be provided whenever necessary. ${ }^{46}$

\section{CONCLUSION}

This is the first prospective clinical study which has evaluated and compared the efficacy of oral Cephalexin against Doxycycline in acne vulgaris in terms of reduction in comedone count as well as inflammatory lesion count in an open label randomized controlled manner involving a hospital based population. Though both Cephalexin and Doxycycline have significantly reduced the counts after eight weeks of therapy, the latter appeared to be a better therapeutic option. Both the drugs displayed similar safety profile without any serious adverse events. However, considering its usefulness in other skin infections and the cost factor attached Cephalexin's indication in inflammatory acne vulgaris remains limited to the patients in whom other oral antibiotics are contraindicated or not tolerated.

\section{Funding: No funding sources}

Conflict of interest: None declared

Ethical approval: The study was approved by the Institutional Ethics Committee

\section{REFERENCES}

1. Burton JL, Cunliffe WJ, Stafford I, Shuster S. The prevalence of acne vulgairs in adolescence. British Journal of Dermatology. 1971;85:119-26.
2. Lawley LP, McCall CO, Lawley TJ. Eczema, Psoriasis, Cutaneous infections, Acne, and Other Common Skin Disorders. In: Longo DL, Fauci AS, Kasper DL, Hauser SL, Jameson JL, Loscalzo J eds. Harrison's Principles of Internal Medicine. $18^{\text {th }}$ Ed. New York: McGraw Hill; 2012:1:403-404.

3. Kathani Amin MD, Christy C R, Daniel J, Eric S. Common and alternate oral antibiotic therapies for acne vulgaris: a review. Journal of Drugs in Dermatology. 2007;6:873-80.

4. Oudenhoven MD, Kinney MA, McShane DB, Burkhart CN, Morrell DS. Adverse effects of acne medications: recognition and management. Am J Clin Dermatol. 2015.Aug;16(4):231-42.

5. Wu SF, Kinder BN, Trunnell TN, Fulton JE. Role of anxiety and anger in acne patients: a relationship with the severity of the disorder. Journal of the American Academy of Dermatology. 1988 Feb 1;18(2):325-33.

6. Cotterill JA, Cunliffe WJ. Suicide in Dermatological patients. British Journal of Dermatology. 1997; 137:246-50.

7. Tan JK. Psychological impact of acne vulgairs. Skin therapy. 2004;9:1-39.

8. Ochsendorf F. Systemic antibiotic therapy of acne vulgaris. J Dtsch Dermatol Ges. 2006;4828-41.

9. Strauss JS, Krowchuk DP, Leyden JJ, Lucky AW, Shalita AR, Siegfried EC, et al. Guidelines of care for acne vulgaris management. J Am Acad Dermatol. 2007;56:651-63.

10. Rathi S. Acne vulgaris treatment: the current scenario. Indian J Dermatol. 2011:56(1):7-13.

11. Tanghetti EA, Popp KF. A current review of topical benzoyl peroxide: new perspectives on formulation and utilization. Dermatol Clin. 2009Jan;27(1):17-24.

12. Fenner JA, Wiss K, Levin NA. Oral Cephalexin for acne vulgaris: Clinical experience with 93 patients. Pediatric Dermatology. 2008;25(2):179-83.

13. Leyden, J. Current issues in antimicrobial therapy for the treatment of acne. Journal of the European Academy of Dermatology and Venereology, December 2001;15(3):51-5.

14. Sykes NL, Webster GF. Acne. A review of optimum treatment. Drugs 1994;48:59-70.

15. Sheeler RD. Cephalosporin for acne vulgaris. J Am Acad Dermatol. 1986;16:1091.

16. Kurokawa I, Nishijima S, Kawabata S. Antimicrobial susceptibility of Propionibacterium acnes isolated from acne vulgaris. Eur J Dermatol. 1999 JanFeb;9(1):25-8.

17. Nishijima S, Kurokawa I, Kawabata S. Sensitivity of Propionibacterium acnes isolated from acne patients: comparative study of antimicrobial agents. J Int Med Res. 1996 Nov- Dec;24(6):473-7.

18. Cunliffe WJ, Gould DJ. Prevalence of facial acne vulgaris in late adolescence and in adults. BMJ. 1979;1:1109-10.

19. Picardi A, Abeni D, Melchi CF, Puddu P, Pasquini P. Psychiatric morbidity in dermatological outpatients: an issue to be recognized. $\mathrm{Br} \mathrm{J}$ Dermatol. 2000;143:983-91. 
20. Kellet SC, Gawkrodger DJ. The psychological and emotional impact of acne and the effect of treatment with isotretinoin. Br J Dermatol. 1999;140:273-82.

21. Keri J, Shiman M. An update on the management of acne vulgaris. Clinical, Cosmetic and Investigational Dermatology. 2009;2:105-10.

22. Bowe WP. Antibiotic resistance and acne: where we stand and what the future holds. J Drugs Dermatol. 2014 Jun;13(6):s66-70.

23. Johnson BA. Use of systemic agents in the treatment of acne vulgaris. American Family Physician. 2000;42:1823-30,1835-6.

24. Di Caprio R, Lembo S, Di Costanzo L, Balato A, Monfrecola G. Anti-inflammatory properties of low and high doxycycline doses: an in vitro study. Mediators Inflamm. 2015;2015:329418.

25. Kramer PA, Chapron DJ, Benson J, Mercik SA. Tetracycline absorption in elderly patients with achlorhydria, Clinical Pharmacology and Therapeutics. 1978;23(4):467-72.

26. Klein NC, Cunha BA. Tetracyclines, Medical Clinics of North America. 1995;79(5):789-801.

27. Bahrami F, Morris DL, Pourgholami MH. Tetracyclines: drugs with hugetherapeutic potential. Mini Rev Med Chem. 2012 Jan;12(1):44-52.

28. Sapadin AN, Fleischmajer R. Tetracyclines: nonantibiotic properties and their clinical implications. J Am Acad Dermatol. 2006 Feb;54(2):258-65.

29. Dormn G, Cseh S, Hajd I. Matrix metalloproteinase inhibitors: a critical appraisal of design principles and proposed therapeutic utility, Drugs. 2010;70(8):94964.

30. Meyer-Hoffert. Reddish, scaly, and itchy: how proteases and their inhibitors contribute to inflammatory skin diseases, Archivum Immunologiaeet Therapiae Experimentalis. 2009;57(5):345-54.

31. Sinclair W, Jordaan HF. Global Alliance to Improve Outcomes in Acne.Acne guideline 2005 update. S Afr Med J. 2005 Nov;95(11 Pt 2):881-92.

32. Skidmore R, Kovach R, Walker C, Thomas J, Bradshaw M, Leyden $\mathrm{J}$, et al. Effects of subantimicrobial-dose doxycycline in the treatment of moderate acne. Arch Dermatol. 2003 Apr;139(4):459-64.

33. Toossi P, Farshchian M, Malekzad F, Mohtasham N, Kimyai-Asadi A. Subantimicrobial-dose doxycycline in the treatment of moderate facial acne. J Drugs Dermatol. 2008 Dec;7(12):1149-52.

34. Moore A, Ling M, Bucko A, Manna V, Rueda MJ. Efficacy and Safety of Subantimicrobial Dose, Modified-Release Doxycycline $40 \mathrm{mg}$ Versus Doxycycline $100 \mathrm{mg}$ Versus Placebo for the treatment of Inflammatory Lesions in Moderate and Severe Acne: A Randomized, Double-Blinded, Controlled Study. J Drugs Dermatol. 2015 Jun 1;14(6):581-6.
35. Kubba R, Bajaj AK, Thappa DM, Sharma R, Vedamurthy M, Dhar S, et al. Indian Acne Alliance (IAA). Acne in India: guidelines for management IAA consensus document. Indian $\mathrm{J}$ Dermatol Venereol Leprol. 2009 Jan;75(1):1-62.

36. Miyachi Y, Yoshioka A, Imamura S, Niwa Y. Effect of antibiotics on the generation of reactive oxygen species. J Invest Dermatol. 1986 Apr;86(4):449-53.

37. Veinberg G, Vorona M, Shestakova I, Kanepe I, Lukevics E. Design of beta-lactams with mechanism based nonantibacterial activities. Curr Med Chem. 2003 Sep;10(17):1741-57.

38. Wilcox HE, Farrar MD, Cunliffe WJ, Holland KT, Ingham E. Resolution of inflammatory acne vulgaris may involve regulation of $\mathrm{CD} 4+\mathrm{T}$-cell responses to Propionibacterium acnes. $\mathrm{Br}$ J Dermatol. 2007 Mar;156(3):460-5.

39. Bayerl C. Acne therapy in pregnancy. Hautarzt. 2013 Apr;64(4):269-73.

40. Pugashetti R, Shinkai K. Treatment of acne vulgaris in pregnant patients. Dermatol Ther. 2013 JulAug;26(4):302-11.

41. Kong YL, Tey HL. Treatment of acne vulgaris during pregnancy and lactation. Drugs. 2013 Jun;73(8):77987.

42. Meredith FM, Ormerod AD. The management of acne vulgaris in pregnancy. Am J Clin Dermatol. 2013 Oct;14(5):351-8.

43. Chien AL, Qi J, Rainer B, Sachs DL, Helfrich YR. Treatment of Acne in Pregnancy. J Am Board Fam Med. 2016 Mar-Apr;29(2):254-62.

44. Giordano PA, Elston D, Akinlade BK, Weber K, Notario GF, Busman TA, et al. Cefdinir vs. cephalexin for mild to moderate uncomplicated skin and skin structure infections in adolescents and adults. Curr Med Res Opin. 2006 Dec;22(12):241928.

45. Sardana K, Gupta T, Kumar B, Gautam HK, Garg VK. Cross-sectional Pilot Study of Antibiotic Resistance in Propionibacterium Acnes Strains in Indian Acne Patients Using 16S-RNA Polymerase Chain Reaction: A Comparison Among Treatment Modalities Including Antibiotics, Benzoyl Peroxide, and Isotretinoin. Indian J Dermatol. 2016 JanFeb;61(1):45-52.

46. Walsh TR, Efthimiou J, Dréno B. Systematic review of antibiotic resistance in acne: an increasing topical and oral threat. Lancet Infect Dis. 2016 Mar;16(3):e23-33.

47. Bowe WP. Antibiotic resistance and acne: where we stand and what the future holds. J Drugs Dermatol. 2014 Jun;13(6):s66-70.

Cite this article as: Banerjee $\mathrm{P}$, Maity $\mathrm{S}$, Bubna A, Das M. A randomized controlled open label comparative clinical study of cephalexin versus doxycycline in patients with acne vulgaris in a hospital based population of South India. Int J Basic Clin Pharmacol 2017;6:1959-64. 